Keywords: immunotoxin; EpCAM; clinical phase l; metastatic disease; anti-immunotoxin antibodies; immunosuppression; cyclosporin

\title{
Phase I trial of EpCAM-targeting immunotoxin MOC31PE, alone and in combination with cyclosporin
}

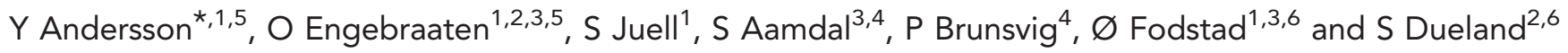 \\ ${ }^{1}$ Department of Tumor Biology, Institute for Cancer Research, Oslo University Hospital Radiumhospitalet, 0424 Oslo, Norway; \\ ${ }^{2}$ Department of Oncology, Oslo University Hospital, 0424 Oslo, Norway; Institute of Clinical Medicine, Faculty of Medicine, \\ University of Oslo, 0424 Oslo, Norway and ${ }^{4}$ Department of Clinical Cancer Research, Oslo University Hospital Radiumhospitalet, \\ 0424 Oslo, Norway
}

Background: A phase I trial was performed to determine the maximum tolerated dose (MTD), safety, pharmacokinetics and immunogenicity of the anti-EpCAM immunotoxin (IT) MOC31PE in cancer patients. An important part of the study was to investigate whether the addition of Sandimmune (cyclosporin, CsA) suppressed the development of anti-IT antibodies.

Methods: Patients with EpCAM-positive metastatic disease were eligible for treatment with intravenous MOC31PE using a modified Fibonacci dose escalation sequence. Maximum tolerated dose was first established without, then with intravenously administered CsA.

Results: Sixty-three patients were treated with MOC31PE in doses ranging from 0.5 to $8 \mu \mathrm{g} \mathrm{kg}^{-1}$. Maximum tolerated dose was $8 \mu \mathrm{g} \mathrm{kg}^{-1}$ for MOC31PE alone, and $6.5 \mu \mathrm{g} \mathrm{kg}^{-1}$ when combined with CsA. The dose-limiting adverse event was reversible liver toxicity. No radiological complete or partial responses were observed, whereas stable disease was seen in $36 \%$ of the patients receiving MOC31PE only. The pharmacokinetic profile of MOC31PE was characterised by linear kinetics and with a half-life of $\sim 3 \mathrm{~h}$. The addition of CsA delayed the generation of anti-IT antibodies.

Conclusions: Intravenous infusion of MOC31PE can safely be administered to cancer patients. Immune suppression with CSA delays the development of anti-MOC31PE antibodies. The antitumour effect of MOC31PE warrants further evaluation in EpCAMpositive metastatic disease.

Tumour therapies targeting EpCAM have been extensively investigated, particularly because the antigen is overexpressed in epithelial tumours, cancer stem cells and circulating tumour cells (van der Gun et al, 2010; Schnell et al, 2013). The therapeutic strategies include both naked antibodies and antibodies armed with a cell killing moiety, for example, cytotoxic drugs or toxins. Immunotoxins (ITs) are bifunctional proteins composed of an antibody and a toxin moiety (Alewine et al, 2015). In cancer, the antibody can deliver the toxin to cell-surface antigens expressed on the malignant cells, theoretically leaving normal cells unaffected. When internalised into the cells, the toxin moiety triggers cell death by catalytically inactivating vital processes, such as protein synthesis, and by directly inducing apoptosis (Andersson et al, 2004; Antignani and Fitzgerald, 2013).

The first-generation ITs consisted of an intact murine monoclonal antibody covalently linked to the whole toxin, later followed by the second generation in which the cell binding domain of the toxin was deleted (Antignani and Fitzgerald, 2013). The third

\footnotetext{
*Correspondence: Dr Y Andersson; E-mail: yvonne.andersson@rr-research.no

${ }^{5}$ These authors contributed equally to this work.

${ }^{6}$ These authors contributed equally to this work
}

Received 19 March 2015; revised 15 September 2015; accepted 6 October 2015; published online 10 November 2015 
generation of ITs consists of recombinant ITs (Antignani and Fitzgerald, 2013), supposed to be better tailored to their purpose. Their small size would assure better tumour penetration, and the immunogenic fragments and non-specific targeting moieties were modified. Unfortunately, none of the clinical trials with ITs in solid tumours has so far been successful. The only first-generation IT containing intact Pseudomonas exotoxin A (PE) previously studied in a phase I trial is OVB3-PE (Pai et al, 1991). OVB3-PE was given intraperitoneally to patients with ovarian cancer, but no antitumour activity was observed. The target antigen was found to be expressed also in CNS, and this resulted in dose limiting toxicity (DLT) and even had lethal consequences.

The importance of antibody selection and antigen specificity has been experienced in several clinical trials (Pai-Scherf et al, 1999), and unanticipated clinical toxicity of many ITs, such as vascular leak syndrome (VLS) and neurotoxicity, seems to be caused mainly by non-specific binding of the targeting antibody (Andersson et al, 2009).

The use of native PE linked to mouse monoclonal antibodies has raised critical concerns. Therefore, modified PE, mostly PE38 that lacks domain I, have been preferred. A clinical trial in epithelial tumours with the PE38-based IT, LMB-1, was reported back in 1996. Vascular leak syndrome was the major toxicity (Pai et al, 1996), but antitumour activity for some months was observed in $13 \%$ of the patients. Other recombinant ITs have, in spite of promising preclinical results, either failed to generate responses in patients, or caused undesired and sometimes serious side effects (e.g., hepatotoxicity, neurotoxicity, and VLS) and induced a strong human anti-IT antibody response (Antignani and Fitzgerald, 2013).

The only FDA-approved IT for systemic use is Denileukin diftitox (Ontak) for treatment of T-cell lymphoma, but it caused several serious adverse events (McCann et al, 2012). During the course of the present study, another EpCAM targeting IT, the recombinant scFv-truncated PE fusion construct VB4-845, was given intravesically in patients with bladder cancer, and intratumorally in head and neck cancer. Some evidence of antitumour effect and limited drug-related toxicity was reported (MacDonald et al, 2009; Kowalski et al, 2010), but to our knowledge VB4-845 has not been administered intravenously (i.v.). In retrospect, it is clear that in spite of all technological advances in the development of second and third generation of ITs, they have not fulfilled the expectations, with hepatotoxicity as the most common side effect. We have previously shown that our MOC31PE IT, consisting of a murine monoclonal antibody covalently linked to intact PE, had potent antitumour effects in vitro and in animal models (Engebraaten et al, 2000; Andersson et al, 2004, 2009; Hjortland et al, 2004; Risberg et al, 2010, 2011; Flatmark et al, 2013; Wiiger et al, 2014).

However, one main limitation with the first-generation ITs is the early development of neutralising antibodies, limiting the efficacy of repeated therapeutic courses. In attempts to overcome this, we tested the combination of the IT and the immunosuppressive drug Sandimmune (cyclosporin, CsA), and found in immunocompetent animals that CsA abrogates the IT-induced immune response. Furthermore, we observed that the combination surprisingly exerted synergistic therapeutic effects in vitro and in a nude rat model for cervical cancer (Andersson et al, 2009), results that encouraged us to initiate a clinical trial with MOC31PE as monotherapy, followed by a combination study with CsA.

\section{MATERIALS AND METHODS}

MOC31PE. The MOC31 monoclonal mouse antibody (IgG1) recognising the CD326 antigen (EpCAM) was produced and purified to clinical grade by MCA Development, Groningen, The Netherlands. PE was isolated from the fermentation broth of Pseudomonas Aeruginosa PA103, manufactured at University of Ohio, Columbus, OH, USA. The MOC31PE conjugate was produced to clinical grade at Fred Hutchinson Cancer Research Center, Biologics Production Facility, Seattle, WA, USA by conjugating MOC31 with PE by a thioether bond formed with the reagent sulfo-SMCC (sulfo-succinimidyl-4-( $N$-maleimidomethyl) cyclohexane-1-carboxylate) (Pierce, Rockford, IL, USA) (Godal et al, 1992). MOC31PE was prepared for clinical use at a concentration of $0.5 \mathrm{mg} \mathrm{ml}^{-1}$ in $20 \mathrm{~mm}$ phosphate-buffered saline (PBS), pH 7.4 and $0.1 \%$ human serum albumin (HSA, clinical grade).

Ethical. The rodent studies were approved by the National Animal Research Authority and carried out according to the European Convention for the Protection of Vertebrates used for Scientific Purposes. The clinical phase I study was approved by the Norwegian Medicines Agency, by the Norwegian Regional Ethical Committee and by the institutional review board. The registration number is NCT01061645 with the study title 'Study of MOC31-PE in antigen positive carcinomas'.

Toxicology studies in mice and monkey. The LD50 level of MOC31PE was assessed in BALB/c mice. MOC31PE $(50,100,150$, 200, 250 and $500 \mu \mathrm{g} \mathrm{kg}^{-1}$ ) were administered by a single i.v. injection, given in a volume of $0.2 \mathrm{ml}$ in $\mathrm{PBS} / 0.1 \% \mathrm{HSA}$ via the lateral tail vein, with a 14 -day observation period. Control animals received vehicle only.

The toxicological evaluation of MOC31PE in cynomologous monkeys (Macaca fascicularis) was performed at Covance Laboratories Inc, Vienna, VA, USA. MOC31PE was administered as a single dose i.v. in two animals per doses $\left(30\right.$ and $150 \mu \mathrm{g} \mathrm{kg}^{-1}$ ) and two animals received repeated dose of $30 \mu \mathrm{g} \mathrm{kg}^{-1}$ at days 1 and 7. Control animals received the drug vehicle. Parameters monitored included clinical symptoms, mortality, changes in body weight and food consumption, haematology, coagulation, and serum biochemical tests were performed on days $2,4,8,15$, and 21 after the first cycle. Each group was observed for at least 2 weeks post injection.

Patients. Eligible patients with metastatic disease were 18 years of age or older with histologically confirmed epithelial carcinoma positive for EpCAM (CD326) by immunocytochemical/immunohistochemical staining. Formalin-fixed paraffin-embedded tumour tissue was stained with the epithelial-specific antigen (ESA) mouse monoclonal antibody (Clone VU-1D9; Novo Castra Laboratories Ltd, Newcastle, UK). For antigen retrieval low $\mathrm{pH}$ and microwave treatment were used, and the antibody staining performed with a $1: 400$ dilution of the primary antibody, and visualised using the Dako EnVision system (Dako, Oslo, Norway). The patients were eligible for inclusion into the study if $10 \%$ or more of the tumour cells were positive for EpCAM/ESA. The patients had to have ECOG performance status $0-2$, neutrophils $\geqslant 1.5 \times 10^{9}$ per litre, platelets $\geqslant 100 \times 10^{9}$ per litre, creatinine $\leqslant 120 \mu \mathrm{moll}^{-1}$, total bilirubin, AST, ALT, ALP, gamma GT (GGT) and coagulation parameters (PT, PTT) all within normal range at the start of the trial.

Major exclusion criteria were clinically symptomatic CNS involvement, the use of coumarin anticoagulants, phenytoin, phenobarbital or systemic steroids, history of hepatitis B or C infection or a HIV diagnosis. Before inclusion and study-related investigations, the patients signed an approved written informed consent.

Study design. The phase I dose escalation trial was performed in two parts, the first with modified Fibonacci dose escalation of MOC31PE alone until the maximally tolerated dose (MTD) was reached, and the second part was performed with dose escalation of MOC31PE and concomitant administration of Sandimmune (CsA; 
Novartis, Oslo, Norway). The starting dose was determined based on the toxicity in mice and non-human primates, with the toxicity in mice species determining the initial dose.

MOC31PE was diluted with $0.9 \%$ saline to a total volume of $250 \mathrm{ml}$, and infused i.v. over $20 \mathrm{~min}$. This combination was repeated every second week up to four times in total. The starting dose was $0.5 \mu \mathrm{g} \mathrm{kg}^{-1}$, and dose escalation was performed at the following schedule: $0.5,1.0,1.5,2.0,3.0,4.0,5.0,6.5$ and $8.0 \mu \mathrm{g} \mathrm{kg}^{-1}$, with at least three patients at each dose level. After an amendment, repeated administration of MOC31PE was allowed up to a total of eight in patients with partial response or stable disease. One patients received eight infusions $\left(0.5 \mu \mathrm{g} \mathrm{kg}^{-1}\right)$ and one six $\left(1.5 \mu \mathrm{g} \mathrm{kg}^{-1}\right)$ infusions.

In the second part of the study, MOC31PE was combined with CsA, administered i.v. over $8 \mathrm{~h}$ at a fixed dose of $3 \mathrm{mg} \mathrm{kg}^{-1}$ at days $0-4$. MOC31PE was administered at day 1 as described above. The dose escalation of MOC31PE was performed at the following levels: 2.0, 3.0, 4.0, 5.0 and $6.5 \mu \mathrm{g} \mathrm{kg}^{-1}$ with at least three patients treated at each dose level. The combination was repeated every second week up to four times in total. In this part of the study, AST, ALT, ALP and GGT values up to $2.5 \times$ upper normal limit at time of inclusion were allowed. In another part of the study, CsA was administered orally, three patients per dose, 3 and $6 \mathrm{mg} \mathrm{kg}$ twice daily (morning and evening), received Sandimmune Soft Gelatin Capsules (CsA oral) at days 0-4 and MOC31PE $\left(4 \mu \mathrm{g} \mathrm{kg}^{-1}\right)$ was administered i.v. at day 1 .

Patient toxicity. Maximally tolerated dose was defined as the dose at which two of up to six patients experienced DLT. DLT was defined as haematological toxicity $\geqslant$ grade 3 , gastrointestinal $\geqslant$ grade 3 , hepatic $\geqslant$ grade 4 , coagulation $\geqslant$ grade 2 , neurological $\geqslant$ grade 2 , renal $\geqslant$ grade 2 or any other $\geqslant$ grade 3 toxicity, according to the National Cancer Institute (NCI) Common Toxicity Criteria (CTC) version 2.0.

Radiology evaluation. Computed tomography (CT) was used to determine tumour response (CR, PR, SD, or PD) by RECIST criteria (Therasse et al, 2000). The CT scans were performed within 4 weeks before first infusion and 8 weeks after first infusion.

Pharmacokinetic analyses of MOC31PE. Blood sampling was performed pre-treatment (baseline) and at five time points after the infusion $(3,6,12,24$ and $48 \mathrm{~h})$ of MOC31PE and the serum was stored frozen until analysed in a quantitative sandwich ELISA to detect MOC31PE. A monoclonal antibody rat anti-mouse IgG1 (LOMG1-13, Abcam, Cambridge, UK) was pre-coated onto a FluoroNunc 96-well plate. Patient serum or standard samples were added into the wells, in addition to the assay buffer (Bjerner et al, 2002). After incubation with shaking for $1 \mathrm{~h}$, rabbit anti-MOC31PE antibodies were added to each well. The rabbit anti-MOC31PE antibodies were affinity purified on a column with human IgG, mouse IgG, goat IgG and human albumin before use. The plate was further incubated for $2 \mathrm{~h}$ and washed six times with washing buffer (PBS containing $0.05 \%$ Tween-20). After washing away any unbound substances, europium goat anti-rabbit IgG was added to the wells and the plate was handled as described (Bjerner et al, 2002).

Quantification of human anti-MOC31PE antibodies in serum. Serum samples for assessing anti-MOC31PE antibodies were taken before dosing on days 1, 14, 28, 42 and 56 and stored frozen until measurement. In each study group, one patient's serum, sampling day 42, was not collected. Two patients in MOC31PE alone were accidentally omitted for serum sampling day 28. Human antiMOC31PE antibodies were detected by using a previously described method with minor modifications (Warren et al, 2005). Biotinylated MOC31 antibodies were attached to streptavidin-coated microplates, by incubation for $30 \mathrm{~min}$ with continuous shaking in room temperature. The plates were washed six times with washing buffer, as above. Patient serum or standard was diluted 1:4 in assay buffer (Bjerner et al, 2002) with addition of $0.1 \%$ Octapharma HSA (Octapharma PPGmbH, Vienna, Austria) to each well. After incubation with shaking for $1 \mathrm{~h}$, the plates were again washed six times and $150 \mu \mathrm{l}$ of europium-labelled tracer antibody conjugated to MOC31PE was added to each well. The plates were thereafter handled as previously described (Warren et al, 2005). The anti-MOC31PE antibody values $\left(\mathrm{AU} \mathrm{ml}{ }^{-1}\right)$ were plotted against a standard curve.

Assessement of the neutralising activity of anti-MOC31PE antibodies. The neutralising effect of human anti-MOC31PE antibodies on MOC31PE-induced inhibition of cell viability was measured using the CellTiter 96 Aqueous One Solution (MTSassay) (Promega, Madison, WI, USA). MA11 breast cancer cells were seeded in 96-well plates at 10000 cells/well and grown to about $80 \%$ confluences in RPMI (Andersson et al, 2004). The old medium was replaced with new medium containing MOC31PE $\left(10 \mathrm{ng} \mathrm{ml}^{-1}\right)$ plus either serum from patients treated with MOC31PE or MOC31PE + CsA or serum sampled before treatment (diluted to $0.25 \%, 0.125 \%, 0.0625 \%$ and $0.03125 \%$ in medium) and incubated at $37^{\circ} \mathrm{C}$ for $24 \mathrm{~h}$. The CellTiter 96 Aqueous One Solution was then added to the wells, and the absorbance was measured 2-4h later at a wavelength of $490 \mathrm{~nm}$. The viability of MOC31PE-treated cells with MOC31PE - or MOC31PE + CsA - patient serum added were compared with the values for untreated control cells and recorded as the percentage cell viability of control cells. The assays were performed in triplicate, and repeated at least three times.

Immunomagnetic detection of micrometastatic cancer cells in bone marrow. Samples of $10-20 \mathrm{ml}$ bone marrow (BM) were aspirated from the posterior iliac crest through aspiration needles, as described (Eide et al, 2009). After BM aspiration, the sample was immediately assayed for the presence of micrometastatic cells. Briefly, the total number of mononuclear cells (MNCs) was counted and the immunomagnetic beads (Dynabeads M450 rat anti-mouse IgG1) coated with MOC31 antibody (IQ Products, Groningen, the Netherlands) were then added to the cell suspension $\left(2 \times 10^{7} \mathrm{MNCs}\right)$. A sample was classified as positive when at least 10 rosetted cells (i.e., cells with membrane-bound beads) out of the total of $2 \times 10^{7} \mathrm{MNC}$ are present. No rosettes were observed with uncoated control beads.

Statistical analysis. Statistical calculations were performed using SSPS version 18.0 (SPSS Inc., Chicago, IL, USA) for Windows. Mann-Whitney and Pearson's Chi square tests were used for statistical analysis. $P<0.05$ was considered to be statistically significant.

\section{RESULTS}

Preclinical toxicity. In preclinical studies, the LD50 of MOC31PE in mice was found to be $100 \mu \mathrm{g} \mathrm{kg}^{-1}$ with an estimated LD10 of $60 \mu \mathrm{g} \mathrm{kg}^{-1}$. According to human equivalent dose (HED), a safe starting dose in humans would be $0.5 \mu \mathrm{g} \mathrm{kg}^{-1}$ (Freireich et al, 1966). Due to the lack of cross reactivity of MOC31 with murine EpCAM, cynomologous monkeys were used for assessing the toxicity of systemically administered MOC31PE $\left(30 \mu \mathrm{g} \mathrm{kg}^{-1}\right)$ as a single dose (two animals) or two doses 1 week apart (two animals) and MOC31PE was well tolerated with no clinical signs, changes in body weight or histopathologic alterations indicating toxicity. The clinical pathology data were indicative of a hepatic insult, with elevation of liver enzymes (AST/ALT) reaching peak values within few days after administration before gradual normalisation. The $30 \mu \mathrm{g} \mathrm{kg}^{-1}$ dose in monkeys is comparable to a dose of $10 \mu \mathrm{g} \mathrm{kg}^{-1}$ in humans (Freireich et al, 1966). 
One monkey (female) given $150 \mu \mathrm{g} \mathrm{kg}^{-1}$ MOC31PE $\left(\mathrm{HED}=50 \mu \mathrm{g} \mathrm{kg}^{-1}\right)$ had a moderate increase in liver enzyme levels (AST (605) and ALT (362) $\left.\left(\mathrm{Ul}^{-1}\right)\right) 2$ days after treatment, and was found dead the following day. Histopathological examination showed diffuse hepatocellular degeneration/necrosis. The other monkey receiving the same dose had a transient increase in liver enzymes with a peak (AST (6480) and ALT (5160) $\left(\mathrm{Ul}^{-1}\right)$ ) 4 days after drug administration before recovering. In this case, focal areas of chronic active inflammation were seen at autopsy at the end of the observation period.

Patient characteristics. This study was conducted in three parts. Thirty-four patients were included in the MOC31PE only part (Table 1). In the second part, IT was administered (day 1) in combination with a fixed i.v. dose of CsA $\left(3 \mathrm{mg} \mathrm{kg}^{-1}\right)$ at days $0-4$ in 23 patients (Table 1).

In the third part of the study, a fixed i.v. dose of MOC31PE $\left(4 \mu \mathrm{g} \mathrm{kg}^{-1}\right.$ day 1$)$ was administered with CsA given orally. Three patients per dose of CsA (3 or $6 \mathrm{mg} \mathrm{kg}^{-1}$ twice daily, days 0-4) were included (Table 1).

Radiological response. Antitumour activity was assessed by CT scan 8 weeks after the first MOC31PE administration. For the 33 patients who could be evaluated for radiological response to MOC31PE alone, no complete or partial responses were obtained, $12(36 \%)$ had stable disease and $21(64 \%)$ had progressive disease.

Table 1. Baseline characteristics of patient populations

\begin{tabular}{|c|c|c|c|}
\hline & $\begin{array}{l}\text { MOC31PE } \\
\text { alone }\end{array}$ & $\begin{array}{c}\mathrm{MOC} 31 \mathrm{PE}+\mathrm{CsA} \\
\text { i.v. }\end{array}$ & $\begin{array}{c}\text { MOC31PE }+ \text { CsA } \\
\text { per os }\end{array}$ \\
\hline Patients, $n$ & 34 & 23 & 6 \\
\hline Age (range) & $57(40-75)$ & $63(47-78)$ & 65 (59-71) \\
\hline \multicolumn{4}{|l|}{ Sex, $n(\%)$} \\
\hline Women & $14(41)$ & $11(48)$ & $3(50)$ \\
\hline Men & $20(59)$ & $12(52)$ & $3(50)$ \\
\hline \multicolumn{4}{|c|}{ ECOG, n (\%) } \\
\hline Grade 0 & $25(74)$ & $14(61)$ & $2(33)$ \\
\hline Grade 1 & $9(26)$ & $8(35)$ & $4(67)$ \\
\hline Grade 2 & $0(0)$ & $1(4)$ & $0(0)$ \\
\hline \multicolumn{4}{|c|}{ Tumour type, $n(\%)$} \\
\hline CRC & $15(44)$ & $18(78)$ & $4(67)$ \\
\hline NSCLC & $12(35)$ & $3(13)$ & $0(0)$ \\
\hline Pancreatic & $3(9)$ & $1(4.5)$ & $2(33)$ \\
\hline Other & $4(12)$ & $1(4.5)$ & $0(0)$ \\
\hline
\end{tabular}

One patient was not evaluated as the patient received only one dose of MOC31PE.

Twenty of the twenty-three patients treated with the combination of MOC31PE + CsA response were evaluated by CT scan, three (15\%) had stable disease and seventeen (85\%) had progressive disease 8 weeks after first infusion of MOC31PE. Two of the patients treated with the highest dose of MOC31PE $\left(6.5 \mu \mathrm{g} \mathrm{kg}^{-1}\right)$ were not examined by CT scan, due to withdrawal from the study after the first dose (increased levels of ALT/AST). One patient at dose $5 \mu \mathrm{g} \mathrm{kg}^{-1}$ was not evaluated by CT scan, because of the patient's own decision to stop treatment after two MOC31PE cycles.

Safety and MTD. The most frequent AEs were hepatobiliary laboratory abnormalities with increased levels of ALT and/or AST, peaking days 3-5, before the levels rapidly decreased to normal in all patients (Table 2).

In MOC31PE administered alone, CTC grade 3 ALT and/or AST abnormalities were detected in the first treatment cycle at dose $3 \mu \mathrm{g} \mathrm{kg}^{-1}$, and grade 4 at $6.5 \mu \mathrm{g} \mathrm{kg}^{-1}$. A total of 13 patients had CTC grade $\geqslant 3$ in ALT and/or AST in cycle 1, but only three of these had elevated levels (grade $\geqslant 3$ ) in cycle 2 . None of these three patients had neutralising anti-MOC31PE antibodies in serum at week 2 . Only three of the thirteen patients had transient grade 1 increase in International normalised ratio (INR). The MTD was determined to be $8 \mu \mathrm{g} \mathrm{kg}^{-1}$, and the DLT observed was transient with AST/ALT levels returning to normal before day 14. Seven patients were included at this dose level, as one patient (normal AST/ALT) only received the first cycle of MOC31PE due to $>1.5$ over normal level for GGT at the time of the second IT dose.

In patients receiving MOC31PE with concomitant CsA, grade 3 toxicity in ALT/AST levels was seen during the first treatment cycle at the $2 \mu \mathrm{g} \mathrm{kg}^{-1}$ dose level, and grade 4 abnormalities appeared at $\geqslant 4 \mu \mathrm{g} \mathrm{kg}^{-1}$ (Table 2).

Fourteen of the twenty-three patients had $\geqslant$ grade 3 ALT/AST toxicity in cycle 1 and six of these had $\geqslant$ grade 3 ALT/AST toxicity also in cycle 2. Interestingly, none of these six patients developed neutralising anti-MOC31PE antibodies even after the third administration of MOC31PE. One patient, at dose level of $6.5 \mu \mathrm{g} \mathrm{kg}^{-1}$, had elevated GGT grade 2 .

The combination of MOC31PE + oral CsA was well tolerated and no co-treatment-related toxicity was registered. However, grade $\geqslant 3$ ALT/AST toxicity was observed in four patients (Table 2).

Other toxicities. No haematological or renal toxicities were observed. Clinical toxicities were mainly minor, with no CTC grade 4 events and only two with CTC grade 3 adverse events; one

Table 2. Number of patients with adverse events after first cycle of MOC31PE

\begin{tabular}{|c|c|c|c|c|c|c|c|c|c|c|c|c|c|c|c|}
\hline & \multicolumn{9}{|c|}{ MOC31PE } & \multicolumn{5}{|c|}{$\mathrm{MOC} 31 \mathrm{PE}+\mathrm{CsA}$ i.v. } & $\begin{array}{c}\text { MOC31PE }+ \text { CsA } \\
\text { per os }\end{array}$ \\
\hline MOC31PE $\left(\mu \mathrm{g} \mathrm{kg}^{-1}\right)$ & 0.5 & 1 & 1.5 & 2 & 3 & 4 & 5 & 6.5 & 8 & 2 & 3 & 4 & 5 & 6.5 & 4 \\
\hline Total patients included & 3 & 3 & 3 & 3 & 3 & 3 & 3 & 6 & 7 & 3 & 3 & 6 & 5 & 6 & 6 \\
\hline $\begin{array}{l}\text { AST/ALT } \\
\text { Grade } 3 \text { ( } n=\text { patient) }\end{array}$ & 0 & 0 & 0 & 0 & 2 & 2 & 2 & 3 & 1 & 2 & 1 & 1 & 1 & 3 & 3 \\
\hline $\begin{array}{l}\text { AST/ALT } \\
\text { Grade } 4 \text { ( } n=\text { patient) }\end{array}$ & 0 & 0 & 0 & 0 & 0 & 0 & 0 & 1 & 2 & 0 & 0 & 1 & 2 & 2 & 1 \\
\hline $\begin{array}{l}\text { Pain/fatigue } \\
\text { Grade } 3 \text { ( } n=\text { patient) }\end{array}$ & 0 & 0 & 0 & 1 & 0 & 0 & 0 & 0 & 0 & 0 & 0 & 0 & 0 & 1 & 0 \\
\hline $\begin{array}{l}\text { Abbreviations: AEs }=\text { advers } \\
\text { administered in the differen } \\
\text { grade } 3 \text { toxicity and fourth } r \\
\text { grade } 3 \text { AEs observed. No } \\
\text { Criteria version } 2.0 \text {. Grade } 3\end{array}$ & AEs th & & icity & & 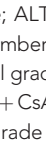 & & & The & 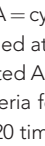 & & acc & nous & $\begin{array}{l}\text { first } \\
\text { vshor } \\
\text { PE dd } \\
\text { Vatior }\end{array}$ & $\begin{array}{l}\text { v shows } \\
\text { he num } \\
\text { level. T } \\
\text { Cancer }\end{array}$ & $\begin{array}{l}\text { the dosage of } \mathrm{MOC} 31 \mathrm{PE} \\
\text { per of patients with clinica } \\
\text { he last row shows the other } \\
\text { Institute Common Toxicity } \\
d \text { with upper normal limit }\end{array}$ \\
\hline
\end{tabular}


patient (MOC31PE alone, $4 \mu \mathrm{g} \mathrm{kg}^{-1}$ ) suffered from pain and one patient (MOC31PE + CsA; $6.5 \mu \mathrm{g} \mathrm{kg}^{-1}$ ) from fatigue and pain. These AEs were most likely related to disease progression, as the two patients had bone metastases and received palliative radiation therapy.

Other minor toxicities (CTC grade 2) were registered in seven patients with MOC31PE (21\%) and six patients with MOC31PE + CsA (22\%) (data not shown). Most of the patients with grade 2 nausea, fatigue or anorexia had these adverse events due to CsA treatment, as they appeared before MOC31PE administration. No adverse events were reported with oral CsA medication. With regard to s-albumin, creatinine, bilirubin, CRP and alkaline phosphate levels only grade 1 toxicities were noted, except that one patient in MOC31PE + CsA (MOC31PE $2 \mu \mathrm{g} \mathrm{kg}^{-1}$, cycle 2) had elevated bilirubin, from 10 to $39 \mu \mathrm{moll}^{-1}$ (grade 2) on day 7 in cycle 2.

MOC31PE pharmacokinetics. The serum level of MOC31PE $3 \mathrm{~h}$ post treatment increased with increasing doses (Figure 1 and Table 3). At $0.5-2 \mu \mathrm{g} \mathrm{kg}^{-1}$ MOC31PE alone, the measured serum level was 8.1 (s.d. $=3.6) \mathrm{ng} \mathrm{ml}^{-1}$. For most patients at dose levels of $3-6.5 \mu \mathrm{g} \mathrm{kg}^{-1}$, the serum contained $>10 \mathrm{ng} \mathrm{ml}^{-1}$ of MOC31PE, even as late as $12 \mathrm{~h}$ post treatment (not shown). Cyclosporin had no influence on MOC31PE serum level (Table 3). The pharmacokinetic curves for MOC31PE at doses from 3 to $6.5 \mu \mathrm{g} \mathrm{kg}^{-1}$ showed similar slopes (Figure 2). The Mann-Whitney Rank sum test on each dose level does not detect any significant difference between the MOC31PE and the MOC31PE + CsA groups. However, the results should be interpreted with caution due to the small number of patients at each dose level.

No serum sample was taken immediately after MOC31PE administration, but estimation of a distribution volume of 3.331 may be used for predicting the initial dose (Gupta et al, 2012). The estimated initial concentration would be $137 \mathrm{ng} \mathrm{ml}^{-1}$ for a $70 \mathrm{~kg}$ patient given $6.5 \mu \mathrm{g} \mathrm{kg}^{-1}$ of MOC31PE. The measured MOC31PE concentration at $3 \mathrm{~h}$ post treatment was $\sim 60 \mathrm{ng} \mathrm{ml}^{-1}$, suggesting that the half-life of MOC31PE is around $3 \mathrm{~h}$ (Figure 2).

CsA delayed anti-MOC31PE antibodies development. The presence of neutralising anti-MOC31PE antibodies in serum was examined in a MOC31PE-induced cytotoxicity assay (MTS assay) (Figure 3 and Supplementary Figure 1a and b). In the presence of anti-MOC31PE antibodies in the serum, the cytotoxic effect of MOC31PE would be partly or fully neutralised.

In MOC31PE alone study, 2 weeks after the first cycle with MOC31PE treatment, 9 of the 29 patients (31\%) had developed neutralising anti-MOC31PE antibodies, compared with only $19 \%$

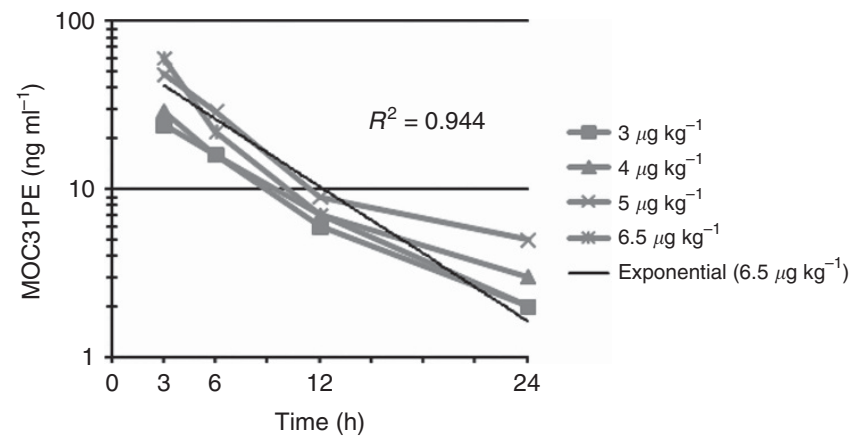

Figure 2. Pharmacokinetics of MOC31PE alone. The plasma levels of MOC31PE were analysed at time points 3, 6, 12, 24 and $48 \mathrm{~h}$ after i.v. injection of MOC31PE. The dose of MOC31PE was 3, 4, 5 and $6.5 \mu \mathrm{g} \mathrm{kg}^{-1}$ ( $n=2-3$ patients/time point). Non-parametric testing using the Mann-Whitney Rank sum test on each dose level does not detect any significant difference between the groups.

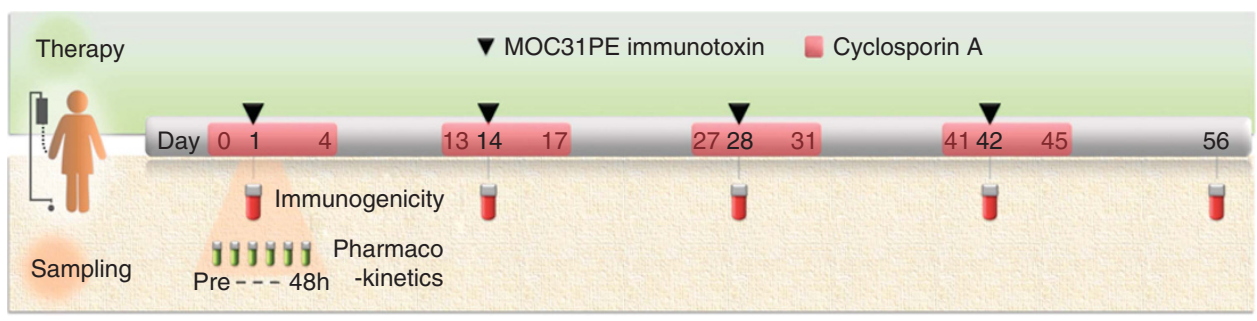

Figure 1. Treatment and blood sampling schedules. MOC31PE was administered as an i.v. infusion every second week, either alone or the day after the first administration of cyclosporin (CsA). CsA was given either i.v. injection or orally, once daily for 5 consecutive days, every second week. Blood sampling for pharmacokinetic studies was done before MOC31PE infusion and 3, 6, 12, 24 and $48 \mathrm{~h}$ after infusion. Blood samples for measuring anti-MOC31PE antibodies were drawn before MOC31PE infusion and every second week before new MOC31PE infusions.

Table 3. Plasma concentration of MOC31PE $3 \mathrm{~h}$ after the first administration cycle of MOC31PE as measured by ELISA

\begin{tabular}{|c|c|c|c|c|}
\hline Dose level $\left(\mu \mathbf{g ~ k g}^{-1}\right)$ & $\begin{array}{l}\text { No. of patients with } \\
\text { serum samples taken in } \\
\text { MOC31PE alone }\end{array}$ & $\begin{array}{c}\text { MOC31PE in } \\
\text { serum } 3 \mathrm{~h} \text { post treatment } \\
\left(\mathrm{ng} \mathrm{ml}^{-1}\right)\end{array}$ & $\begin{array}{l}\text { No. of patients with } \\
\text { serum samples taken in } \\
\text { MOC31PE }+ \text { CsA i.v. }\end{array}$ & $\begin{array}{c}\text { MOC31PE in serum } \\
3 \mathrm{~h} \text { post treatment } \\
\left(\mathrm{ng} \mathrm{ml}^{-1}\right)\end{array}$ \\
\hline 0.5 & 2 & 3,5 & 0 & \\
\hline 1.0 & 3 & $5,9,11$ & 0 & \\
\hline 1.5 & 3 & $4,13,13$ & 0 & \\
\hline 2 & 3 & $6,9,11$ & 3 & $16,18,35$ \\
\hline 3 & 2 & 7,41 & 2 & 13,28 \\
\hline 4 & 3 & $9,30,47$ & 2 & 19,55 \\
\hline 5 & 3 & $44,49,51$ & 2 & 9,49 \\
\hline 6.5 & 2 & 56,63 & 3 & $52,58,73$ \\
\hline
\end{tabular}




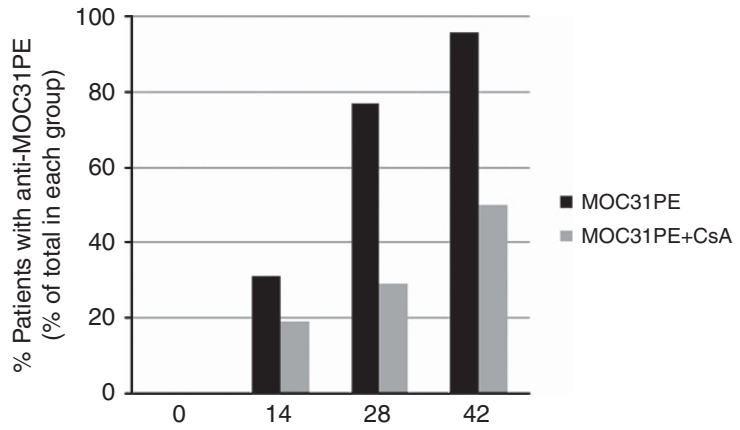

Figure 3. MOC31PE-induced anti-MOC31PE antibody generation was suppressed by CsA. The results from serum taken pre-treatment and at days 14,28 and 42 post treatment are summarised, and the bars show percentage of patients with anti-MOC31PE antibodies. Black bar, MOC31PE alone. Grey bar, MOC31PE + CsA i.v. Each individual serum sample was analysed in triplicates, and at least two independent experiments were run. The Chi-square statistical analysis at both day 28 and day 42 showed significance, $P<0.05$, but not on day 14 .

(4 of 21 patients) in MOC31PE + CsA, most likely reflecting the immunosuppressive function of CsA (Figure 3). However, the statistical difference was not significant. This effect was even more pronounced 2 weeks after the second cycle, where 77\% (24 of 31) of the patients treated with MOC31PE alone had neutralising antibodies, compared with only $29 \%$ (6 of 21 ) of the patients receiving MOC31PE and CsA, $P<0.05$. Moreover, at 6 weeks after treatment start (third cycle of MOC31PE), almost all of the patients in MOC31PE alone had developed antibodies (27 of 28) whereas the immunosuppressive effect of CsA was still clear, as only $50 \%$ (10 of 20) of these patients had antibodies, $P<0.05$. With an ELISA, we measured the levels of anti-MOC31PE antibodies (data not shown). The ELISA data showed an overall accordance to the MTS data. Fetal calf serum and serum from healthy volunteers had no effect on MOC31PE-induced cytotoxicity in MA11 cells (data not shown).

Presence of micrometastatic cancer cells in BM. Bone marrow samples, four out of six patients treated with $4 \mu \mathrm{g} \mathrm{kg}^{-1}$ of MOC31PE and three out of five patients treated with $5 \mu \mathrm{g} \mathrm{kg}^{-1}$, were taken in the MOC31PE + CsA study at baseline and 2 weeks post treatment (Figure 4). No obvious cytotoxic effect of MOC31PE on the presence of micrometastatic cells in BM was detected in patients treated with $4 \mu \mathrm{g} \mathrm{kg}^{-1}$ of MOC31PE. Interestingly, at $5 \mu \mathrm{g} \mathrm{kg}^{-1}$ of MOC31PE the number of EpCAMdetected tumour cells decreased from baseline to 2 weeks post treatment by $36 \%, 74 \%$ and $91 \%$. These patients had no antiMOC31PE antibodies even after four cycles of MOC31PE, indicating that MOC31PE most likely was cytotoxic in all cycles. Mainly due to the lack of consent for BM sampling, none of the patients treated with higher doses of MOC31PE were examined for micrometastatic cancer cells.

\section{DISCUSSION}

In this phase I trial, we have shown that the EpCAM-targeting MOC31PE could safely be administered i.v., and it was well tolerated, both given alone (34 patients) and in combination with CsA (29 patients). Cyclosporin effectively delayed the development of neutralising anti-MOC31PE antibodies, thereby allowing for repeated IT administration.

With the lack of an overall benefit reported in clinical trials with modified and recombinant ITs, we hypothesised that the native functional domains of the toxin should be intact for optimal stability
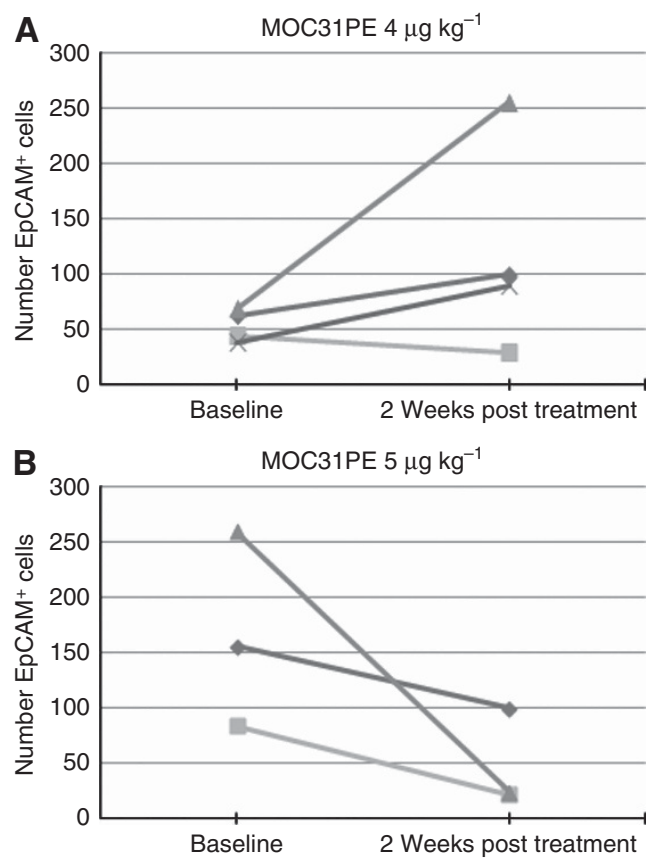

Figure 4. Detection of EpCAM-positive cells in bone marrow samples from patients pre- and 2 weeks post treatment with MOC31PE + CsA. Each line indicates the number of identified rosetted EpCAM-positive cells. The patients received MOC31PE $4 \mu \mathrm{g} \mathrm{kg}^{-1} \mathrm{BW}(\mathbf{A})$. The patients were given MOC31PE $5 \mu \mathrm{g} \mathrm{kg}^{-1} \mathrm{BW}$ (B).

and cytotoxicity, and therefore we developed and characterised our unmodified IT. Based on extensive and promising preclinical studies in vitro and in experimental human tumour models in vivo, we initiated and performed a successful clinical phase I study with MOC31PE in patients with advanced carcinomas. To avoid accumulated toxicity, an administration schedule with IT infusion every other week was chosen. Interestingly, only 3 out of 7 patients treated at the MTD had AST and/or ALT $>5 \times$ the upper limit of normal, and the toxicity was limited to a transient increase in serum transaminases. Apart from hepatotoxicity, only two patients were recorded with grade $3 \mathrm{AEs}$, fatigue and pain, and these AEs were most likely related to disease progression and not MOC31PE according to the clinical disease present.

The adverse event profile of antibody-based drugs varies depending on composition, drug target and the individual patient. MOC31PE recognises the EpCAM antigen that is frequently and highly expressed on epithelial carcinomas. The effect of liver function tests could be attributed to the expression of EpCAM on the small bile ducts (Went et al, 2006). However, in normal tissue, EpCAM is arranged in a complex with several interacting proteins and is localised to basolateral membranes. The accessibility for EpCAM-binding antibodies is lower in normal cells than in cancer cells where EpCAM might be better accessible for targeting antibodies (Schnell et al, 2013). Furthermore, MOC31PE is highly selective for malignant cells, with low toxicity to normal tissues in part due to 'shielding' of EpCAM by the organisation of the surface of the normal epithelial tissues. EpCAM is an interesting target also as EpCAM-positive cancer cells are proposed to be more aggressive than EpCAM-negative cancer cells (van der Gun et al, 2010; Schnell et al, 2013), whereas some groups have reported its expression to be downregulated in, for example, circulating tumour cells (Rao et al, 2005; Steinert et al, 2014). However, our data on breast cancer lymph node cells show EpCAM positive even in tumour cells having undergone epithelial-mesenchymal transition (Tveito et al, 2011). In addition to the MOC31PE alone study, we expanded the phase I trial to include CsA $\left(3 \mathrm{mg} \mathrm{kg}^{-1}\right.$ i.v) in 
combination with MOC31PE. We recently published that CsA efficiently reduced the neutralising anti-IT antibody response when IT was repeatedly administered in immunocompetent animals. Cyclosporin has been shown to enable repeated administration of monoclonal antibody therapy in patients by reducing the human anti-mouse antibody (HAMA) response (Ledermann et al, 1988; Weiden et al, 1994).

No objective tumour response (complete or partial remission) was seen by CT scan 8 weeks after the first MOC31PE infusion. Based on the present knowledge on response to repeated immunotherapy treatment, it is possible that the clinical benefit of the treatment may be underestimated based on only the CT at week 8. In the MOC31PE alone study, 12 patients (36\%) had stable disease compared with only 3 patients (15\%) in the MOC $31 \mathrm{PE}+$ CsA part. However, the incidence of stable disease shows no dose dependency in either the MOC31PE or MOC31PE + CsA arm. Because of the low number of patients at each dose, no clear conclusion can be drawn. Our results imply that the combination of IT + CsA in the clinic may have a promising potential allowing repeated administration of $\mathrm{MOC} 31 \mathrm{PE}$, which is considered to be a necessity for significant anticancer effects in non-haematological cancers. Of note, also oral CsA reduced antibody formation against MOC31PE, and is a more convenient administration for the patient compared with $8 \mathrm{~h}$ i.v. infusion. The presence of micrometastatic cells has been shown to have a prognostic value in patients with metastatic disease (Leong and Tseng, 2014), and EpCAM is a commonly used antigen for detection of circulating tumour cells (Flatmark et al, 2011; Tveito et al, 2011; Rud et al, 2013). This potential surrogate marker might be used to evaluate treatment response to anti-EpCAM targeted therapy. In three patients given $5 \mu \mathrm{g} \mathrm{kg}^{-1}$ of $\mathrm{MOC} 31 \mathrm{PE}+\mathrm{CsA}$, we detected a reduction in micrometastatic cells after treatment. However, too few patients were included to conclude that this was due to MOC31PE antitumour activity.

Another EpCAM-targeting molecule is catumaxomab, a trifunctional antibody. However, there are major dissimilarities between the two drugs mode of action. Catumaxomab must bind three different cell types to exert its effects (Eskander et al, 2013). MOC31PE has an advantage in a 'simpler' mode of action, requiring only recognition of EpCAM-expressing cancer cells.

In conclusion, we have demonstrated that the EpCAM targeted IT MOC31PE can safely be administered i.v. and we present a new strategy permitting administration of repeated doses of IT therapy, viz. by combining IT with CsA to delay the development of neutralising anti-IT antibodies. The encouraging results of this study warrant a phase II study to further examine the potential of MOC31PE as a new anticancer drug. Based on the observed toxicity in this study, the recommended dose for a phase II study will be $6.5 \mu \mathrm{g} \mathrm{kg}^{-1}$ for MOC31PE and $5 \mu \mathrm{g} \mathrm{kg}^{-1}$ for MOC31PE + CsA.

\section{ACKNOWLEDGEMENTS}

We are grateful for the assistance from the study nurse Ingun Flatland Sve. We thank Prof. Kjell Nustad and Kari Hauge Olsen for assistance with ELISA and Dr Ellen Tenstad for valuable contribution to Figure 1. This work was supported by Norwegian Foundation for Health and Rehabilitation, The Norwegian Cancer Society, Norwegian Research Council, South-Eastern Norway Regional Health Authority and Norwegian Radium Hospital legacy

\section{CONFLICT OF INTEREST}

The authors declare no conflict of interest.

\section{REFERENCES}

Alewine C, Hassan R, Pastan I (2015) Advances in anticancer immunotoxin therapy. Oncologist 20: 176-185.

Andersson Y, Engebraaten O, Fodstad O (2009) Synergistic anti-cancer effects of immunotoxin and cyclosporin in vitro and in vivo. Br J Cancer 101: 1307-1315.

Andersson Y, Juell S, Fodstad O (2004) Downregulation of the antiapoptotic MCL-1 protein and apoptosis in MA-11 breast cancer cells induced by an anti-epidermal growth factor receptor-Pseudomonas exotoxin A immunotoxin. Int J Cancer 112: 475-483.

Antignani A, Fitzgerald D (2013) Immunotoxins: the role of the toxin. Toxins 5: $1486-1502$.

Bjerner J, Nustad K, Norum LF, Olsen KH, Bormer OP (2002) Immunometric assay interference: incidence and prevention. Clin Chem 48: 613-621.

Eide N, Faye RS, Hoifodt HK, Overgaard R, Jebsen P, Kvalheim G, Fodstad O (2009) Immunomagnetic detection of micrometastatic cells in bone marrow in uveal melanoma patients. Acta Ophthalmol (Copenh) 87: $830-836$.

Engebraaten O, Sivam G, Juell S, Fodstad O (2000) Systemic immunotoxin treatment inhibits formation of human breast cancer metastasis and tumor growth in nude rats. Int J Cancer 88: 970-976.

Eskander RN, Baruah J, Nayak R, Brueseke T, Ji T, Wardeh R, Tewari KS (2013) Outside slide review in gynecologic oncology: impact on patient care and treatment. Int J Gynecol Pathol 32: 293-298.

Flatmark K, Borgen E, Nesland JM, Rasmussen H, Johannessen HO, Bukholm I, Rosales R, Harklau L, Jacobsen HJ, Sandstad B, Boye K, Fodstad O (2011) Disseminated tumour cells as a prognostic biomarker in colorectal cancer. Br J Cancer 104: 1434-1439.

Flatmark K, Guldvik IJ, Svensson H, Fleten KG, Florenes VA, Reed W, Giercksky KE, Fodstad O, Andersson Y (2013) Immunotoxin targeting EpCAM effectively inhibits peritoneal tumor growth in experimental models of mucinous peritoneal surface malignancies. Int J Cancer 133: 1497-1506.

Freireich EJ, Gehan EA, Rall DP, Schmidt LH, Skipper HE (1966) Quantitative comparison of toxicity of anticancer agents in mouse, rat, hamster, dog, monkey, and man. Cancer Chemother Rep 50: 219-244.

Godal A, Kumle B, Pihl A, Juell S, Fodstad O (1992) Immunotoxins directed against the high-molecular-weight melanoma-associated antigen. Identification of potent antibody-toxin combinations. Int J Cancer 52: 631-635.

Gupta M, Lorusso PM, Wang B, Yi JH, Burris 3rd HA, Beeram M, Modi S, Chu YW, Agresta S, Klencke B, Joshi A, Girish. S (2012) Clinical implications of pathophysiological and demographic covariates on the population pharmacokinetics of trastuzumab emtansine, a HER2-targeted antibody-drug conjugate, in patients with HER2-positive metastatic breast cancer. J Clin Pharmacol 52: 691-703.

Hjortland GO, Garman-Vik SS, Juell S, Olsen OE, Hirschberg H, Fodstad O, Engebraaten $O$ (2004) Immunotoxin treatment targeted to the highmolecular-weight melanoma-associated antigen prolonging the survival of immunodeficient rats with invasive intracranial human glioblastoma multiforme. J Neurosurg 100: 320-327.

Kowalski M, Entwistle J, Cizeau J, Niforos D, Loewen S, Chapman W, MacDonald GC (2010) A phase I study of an intravesically administered immunotoxin targeting EpCAM for the treatment of nonmuscle-invasive bladder cancer in BCGrefractory and BCG-intolerant patients. Drug Des Dev Ther 4: 313-320.

Ledermann JA, Begent RH, Bagshawe KD, Riggs SJ, Searle F, Glaser MG, Green AJ, Dale RG (1988) Repeated antitumour antibody therapy in man with suppression of the host response by cyclosporin A. Br J Cancer 58: 654-657.

Leong SP, Tseng WW (2014) Micrometastatic cancer cells in lymph nodes, bone marrow, and blood: Clinical significance and biologic implications. CA Cancer J Clin 64: 195-206.

MacDonald GC, Rasamoelisolo M, Entwistle J, Cizeau J, Bosc D, Cuthbert W, Kowalski M, Spearman M, Glover N (2009) A phase I clinical study of VB4-845: weekly intratumoral administration of an anti-EpCAM recombinant fusion protein in patients with squamous cell carcinoma of the head and neck. Drug Des, Dev Ther 2: 105-114.

McCann S, Akilov OE, Geskin L (2012) Adverse effects of denileukin diftitox and their management in patients with cutaneous T-cell lymphoma. Clin J Oncol Nurs 16: E164-E172. 
Pai-Scherf LH, Villa J, Pearson D, Watson T, Liu E, Willingham MC, Pastan I (1999) Hepatotoxicity in cancer patients receiving erb-38, a recombinant immunotoxin that targets the erbB2 receptor. Clin Cancer Res 5: 23112315.

Pai LH, Bookman MA, Ozols RF, Young RC, Smith 2nd JW, Longo DL, Gould B, Frankel A, McClay EF, Howell S, Reed E, Willingham MC, FitzGerald DJ, Pastan I (1991) Clinical evaluation of intraperitoneal Pseudomonas exotoxin immunoconjugate OVB3-PE in patients with ovarian cancer. J Clin Oncol 9: 2095-2103.

Pai LH, Wittes R, Setser A, Willingham MC, Pastan I (1996) Treatment of advanced solid tumors with immunotoxin LMB-1: an antibody linked to Pseudomonas exotoxin. Nat Med 2: 350-353.

Rao CG, Chianese D, Doyle GV, Miller MC, Russell T, Sanders Jr. RA, Terstappen LW (2005) Expression of epithelial cell adhesion molecule in carcinoma cells present in blood and primary and metastatic tumors. Int J Oncol 27: 49-57.

Risberg K, Fodstad O, Andersson Y (2010) Anti-melanoma activity of the 9.2.27PE immunotoxin in dacarbazine resistant cells. J Immunother 33 272-278.

Risberg K, Fodstad O, Andersson Y (2011) Synergistic anticancer effects of the 9.2.27PE immunotoxin and ABT-737 in melanoma. PLoS One 6: e24012.

Rud AK, Borgen E, Maelandsmo GM, Flatmark K, Le H, Josefsen D, Solvoll I, Schirmer CB, Helland A, Jorgensen L, Brustugun OT, Fodstad O, Boye K (2013) Clinical significance of disseminated tumour cells in non-small cell lung cancer. Br J Cancer 109: 1264-1270.

Schnell U, Cirulli V, Giepmans BN (2013) EpCAM: structure and function in health and disease. Biochim Biophys Acta 1828: 1989-2001.

Steinert G, Scholch S, Niemietz T, Iwata N, Garcia SA, Behrens B, Voigt A, Kloor M, Benner A, Bork U, Rahbari NN, Büchler MW, Stoecklein NH, Weitz J, Koch M (2014) Immune escape and survival mechanisms in circulating tumor cells of colorectal cancer. Cancer Res 74: 1694-1704.

Therasse P, Arbuck SG, Eisenhauer EA, Wanders J, Kaplan RS, Rubinstein L, Verweij J, Van Glabbeke M, van Oosterom AT, Christian MC,
Gwyther SG (2000) New guidelines to evaluate the response to treatment in solid tumors. European Organization for Research and Treatment of Cancer, National Cancer Institute of the United States, National Cancer Institute of Canada. J Natl Cancer Inst 92: 205-216.

Tveito S, Andersen K, Karesen R, Fodstad O (2011) Analysis of EpCAM positive cells isolated from sentinel lymph nodes of breast cancer patients identifies subpopulations of cells with distinct transcription profiles. Breast Cancer Res 13: R75.

van der Gun BT, Melchers LJ, Ruiters MH, de Leij LF, McLaughlin PM, Rots MG (2010) EpCAM in carcinogenesis: the good, the bad or the ugly. Carcinogenesis 31: 1913-1921.

Warren DJ, Bjerner J, Paus E, Bormer OP, Nustad K (2005) Use of an in vivo biotinylated single-chain antibody as capture reagent in an immunometric assay to decrease the incidence of interference from heterophilic antibodies. Clin Chem 51: 830-838.

Weiden PL, Wolf SB, Breitz HB, Appelbaum JW, Seiler CA, Mallett R, Bjorn MJ, Su FM, Fer MF, Salk D (1994) Human anti-mouse antibody suppression with cyclosporin A. Cancer 73: 1093-1097.

Went P, Vasei M, Bubendorf L, Terracciano L, Tornillo L, Riede U, Kononen J, Simon R, Sauter G, Baeuerle PA (2006) Frequent high-level expression of the immunotherapeutic target Ep-CAM in colon, stomach, prostate and lung cancers. Br J Cancer 94: 128-135.

Wiiger MT, Bideli H, Fodstad O, Flatmark K, Andersson Y (2014) The MOC31PE immunotoxin reduces cell migration and induces gene expression and cell death in ovarian cancer cells. J Ovarian Res 7: 23.

This work is published under the standard license to publish agreement. After 12 months the work will become freely available and the license terms will switch to a Creative Commons AttributionNonCommercial-Share Alike 4.0 Unported License.

Supplementary Information accompanies this paper on British Journal of Cancer website (http://www.nature.com/bjc) 